FED REACTOR ENGINEERING FEATURES*

\title{
DES4 004451
}

\author{
P. H. Sager, ${ }^{1}$ T. G. Brcwn, ${ }^{2}$ G. M. Fuller, ${ }^{3}$ and G. E. Smith ${ }^{2}$ \\ Fusion Engineering Design Center \\ Oak Ridge Naticrial Laboratory \\ Oak Rjdge, Tennessee, USA
}

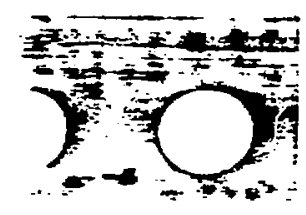

The Fusion Engineering Device (FED) Baseline design incorporates a number of features which were selected to enhance its maintainability, as well as limit cost and achieve reliable operation. An installation of ten IF coils and ten torus sectors was selected on the basis of plasma chamber segmentation studies and TF coil cost tradeofi studies, permitting removal of a torus sector with a single radial motion. The design also features a shield sector s'pport spool which provides a plasma chamber vacuum boundary and access to the shield sectors. The vacuum seals are made at the outboard face of the torus so that they can be readily cut and rewelded. A pumped limiter provides plasma edge definition and impurity control. Ten individual blades are inserted through tha shield sector in an arrangecent that permits replacement without sector removal. ICRH is used for plaswa bulk heating. Tro EF coils, which are located inside the TF coil bore, are segmented so that they can be removed if necessary. The removal of the superconducting lower outboard EF coil, which is trapped under the TF coil assembly, presents a problem; consideration is being given to increasing its diameter and relocating it so shat it can be lifted up around the TF coils.

\section{INTRODUCTION}

The design of a near-term Fusion Engineering Device (FED) has been developed. The mission of this reactor is to $/ 1 /$ :

1) achieve the sustained production of fusion power in order to extract power fron a b:anket module under prototypical conditicns,

2) demonstrate a full fuel eycle operation to assure fuel self-sufficiency for a fusion demonstration plant, and

3) demonstrate the construction, safe operation, and maintainability of a device integrating technologies representative of a fusion demonstration plant.

In saveloping the design of the FED, consideration has been given to maintainability, as well as $t_{1}$ : cost, performance, and reliability. These factors are not always compatible, and in some cases the design solution reflects a compromise among competing considerations. Cost and performance are the major drivers in the selection of the machine basic paraveters; in general, the machine cost is approximately proportional to the $R^{2}$ ( $R=$ major radius), so the machine is made as small as possible for a given performance requirement. Arong the features dictated at least in part by maintenance considerations are the number of TF coils, segmentation of the torus, impurity control system, plasma heating system, and PF coil installation.

* Research sponsored by the Office of Fusion Energy, US. Department of Energy, under contract $W-7405-$ eng-26 with the Union Carbide Corporation and contract DE-AT03-76ET51011 with Generai Atomic Company.

${ }^{1}$ General Atomic Company, ${ }^{2}$ Grumman Aerospace Corporation, ${ }^{3}$ McDonnell Douglas Astronautics Company.

\section{DISCLAIMER}

This report was prepared as an account of work sponsored by an agency of the United States Government. Neither the United States Government nor any agency thereof, nor any of their employees, makes any warranty, express or implied, or assumes any legal liability or responsibility for the accuracy, completeness, or usefulness of any information, apparatus, product, or process disclosed, or represents that its use would not infringe privately owned rights. Reference herein to any specilic commercial product, process, or service by trade name, trademark, manufacturer, or otherwise does not necessarily constitute or imply ils eodorsement, recommendation, or favoring by the United States Government or any agency thereof. The views and opinions of authors expressed herein do not necessarily state or reflect thoee of the United States Government or any agency thereof.

\section{MOTIEE} POATIONS OF THIS REPOAT ANE ILUEGLE

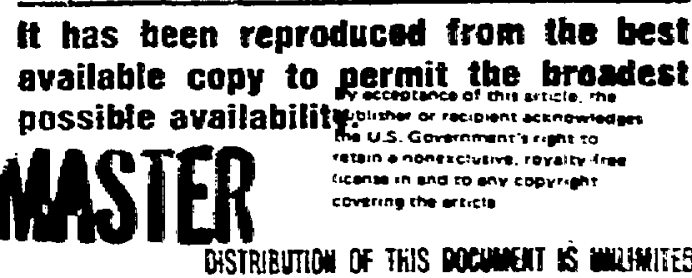




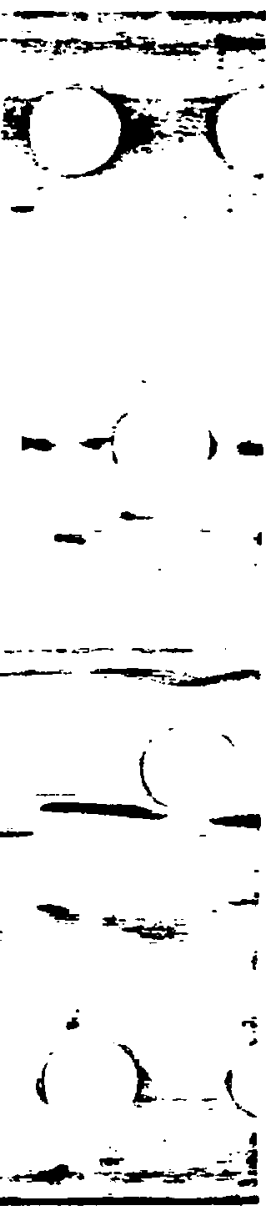

\section{OVERALL DESIGN}

The overall design of the FED $/ 2 /$ is presented in figs. 1 and 2 . The pajor design parameters are iisted in Table 1. It should be noted that the FED is designed to reach ignizion at a maximum toroidal field of $10 \mathrm{~T}$ but that most of the engineering testing will be performed at $8 \mathrm{~T}$.

Table I. Key Design Parameters.

8 Tesla

Major radius (m)

Plasma radius (m)

Plasma elongation

Fusion power (MW)

Average neutron wall load $\left(\mathrm{mW} / \mathrm{m}^{2}\right)$

Peak neutron wall load $\left(\mathrm{MW} / \mathrm{m}^{2}\right)$

Heating power (MW) Initial

Burn

$Q$

Burn time (s)

Duty factor

Average D-T density $\left(\mathrm{m}^{-3}\right)$

Average total beta $(\%)$

Plasma current (MA)

Clear bore, width $x$ height (m)

Field on axis ( $T$ )

Number of full field pulses

Availability $(\%)$

The toroidal field (TF) coil system is comprised of $10 \mathrm{Mbi} 1$ superconducting coils tied together with an intercoil support structure and supyorted by neans of epoxy-fiberglass support columns. The centering forces are reacted by both the wedging action between the coil cases of adjacent coils and a stainless steel bucking post.

The plasma chamber is comprised of an assembly of ten stainless steel shield sectors inserted into a support spcol structure.

The arrangement of ten TF coils and ten shield sectors was selected on the basis of providing for complete removal of the first wall with the shield sectors while minimizing overall cost. Earlier studies $/ 3 /$ indicated that costs tend to optimize in the range of 16 to 20 TF coils. Access is considerably improved, however, and the cost penalties are not severe for designs with as few as 10 to 12 coils.

Inside the torus assembly, graphite tiles are installed on the inboard and top walls to provide protection against plasma distuptions. Bare stainless steel panels are installed along the three facets of the outboard wall, which is less likely to encounter the inpact of plasma disruptions. A purped limiter is installed in the bottom of the chamber. ECRH launchers, which are used to assist in startup, are installed in the top of each of the ten shield sectors. ICRH launchers for bulk heating are installed in the outboard wall of each of four adjacent shield sectors. A dual set of pellet injectors is also installed in the outboard wall of one of the shield sectors.

The poloidal field (PF) coil system includes a superconducting solenoid, two superconducting equilibrium field (EF) coils located outside the TF coils, and two normal conducting EF coils located inside the TF coil bore. The soienoid coil contributes to the establishzent of the equilibrium field and provides for ohmic heating of the plasma and naintaining plasma current. 


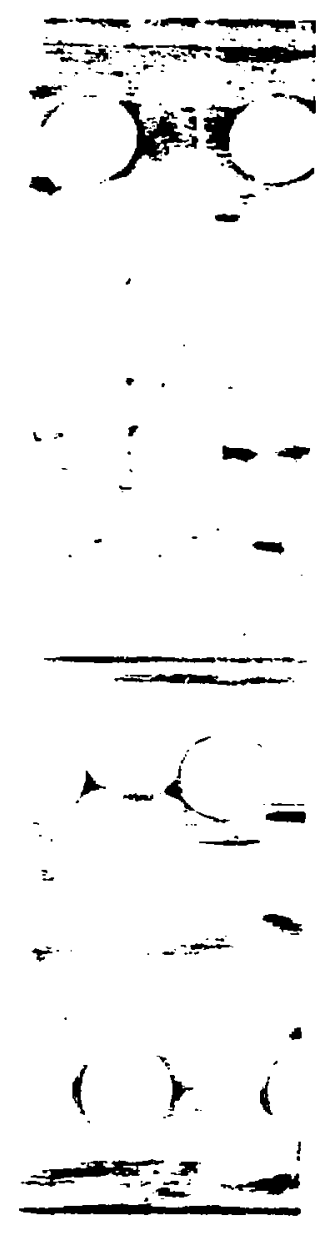

\section{PLASMA CHAMBER VACUUM BOUNDARY}

Accessibility was identified as the princifle concern in establishing the vacuum boundary of the FED. An additional concern was the potential problem of weld repair in the inside of the plasma chamber after exposure to a high level of neutron fluence. A siudy of these problems indicated that the most accessibie arrangement could be provided by establishing the vacuum boundary at the outside of the torus by means of a spool structure (fig. 3) into which the shield sectors (fig. 4) are inserted, with the sea! between the sectors and the spool being located at the outboard face of the spool.

This design concept mikes it possible to mount and monitor the weld cutting and reweiding appertures using personnel stationed at the work site and to install the handling equipmnnt using contact precedures.

\section{SHIELDING}

A review of current experimental fusion reactors indicates that most of the maintenance operations involve minor repairs (e.g., leaks and loose connecticns) to diagnostics, controls, and service systems outside the reactor. These maintenance operations usually are unplanned and frequently wouid pose access problems for renote maintenance equipuent. Accordingly, it was decided to provide adequate bulk shield so that personnel access could be gained 24 hours after reactor shutdown.

The FED includes 1.15 m of stainless steel (Nitronic 33) and water shield, plus $5 \mathrm{~cm}$ of lead on the top, bottom, and outboard regions. Calculations $/ 2 /$ indicate that the dose rate is reduced to $2.5 \mathrm{mrem} / \mathrm{hr} 24$ hours after shutdown from 8-T operation, permitting access to tho reactor outside the bulk shield. (Thirty-six hours is required to reach this level after 10-T operation.)

Diagnostics, test modules, and other penetrations pose problems in tertss of local shielding and activaticn. Extra shielding (fig. 5) is provided to treat these situations, and it will undoubtedly be necessary to restrict access and/or provide portable shielding in excessively activated areas during maintenance operations. In some cases, access can be gained to highly activated areas for short periods where the total exposure of specific individuals is limited.

5. IMPURITY CONTROL

A punped ligiter was selected to provide impurity control of the FED (fig. 6). A flat limiter surface was chosen to provide for flexibility in plasma surface configuration and radial position.

Since the plasma edge conditions are unknown, the erosion rate of the graphite tiles covering the limiter blades is uncertain. Calculations based on a range of poss ble conditions, however, indicate that the limiter blade life may be very short--as little as a few months. Accordingly, provisions are made for readily replacing the limiter blade. Al: service connections and the vacuum seal flange are located outside the bulk shield so that the blade can be disconnected using contact procedures. The actual removal of the eroded blade and insertion of the new or renovated blade, however, are accomplished by remote handling techniques. 


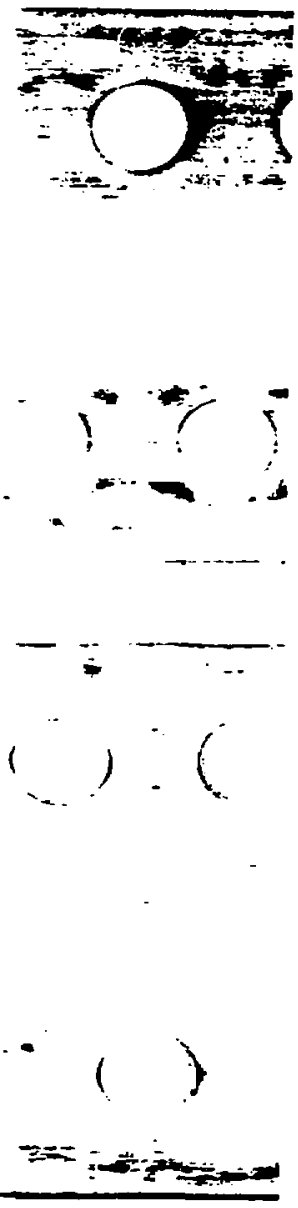

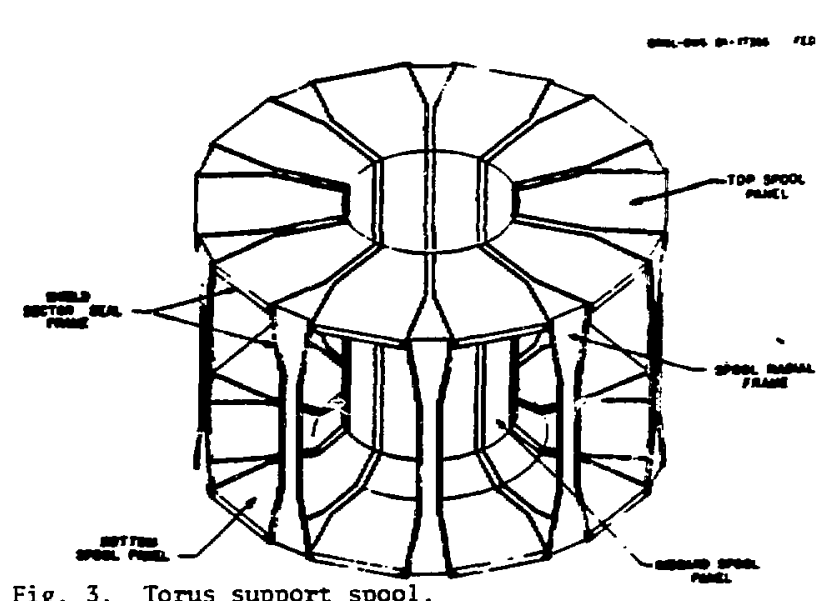

Fig. 3. Torus support spool.

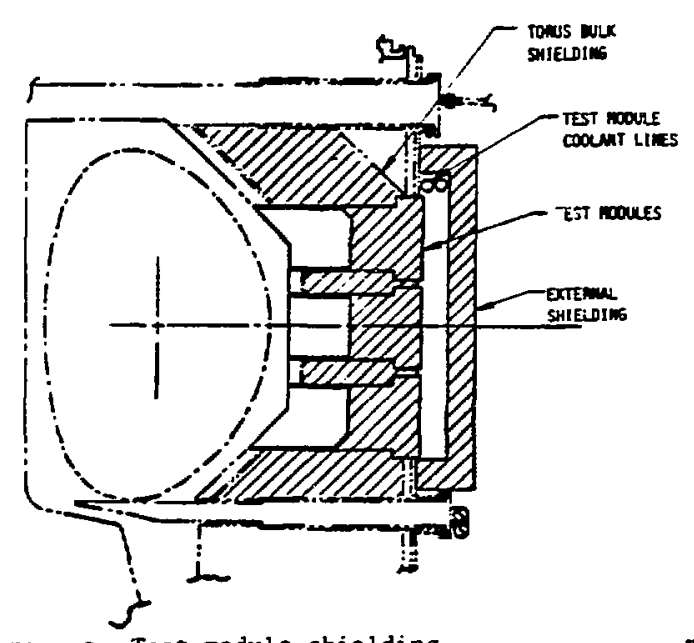

Fig. 5. Test module shielding.

6. FIRST WALL COMPONENTS

It was concluded chat, while it may be possible to map operating paraseters so as to operate in a "disruption free" mode, it is still necessary to protect the inside of the plasma chamber from damage due to disruptions resulting from control system failures. Movement of the plasma to the inboard wall or in a vertical direction is predicted for such a failure mode. Accordingly, the top, bottom, and irboard walls of the shield sectors are protected with graphite tiles (Fig. 7).

The graphite tiles, which are nominally $5 \mathrm{~cm}$ thick, are attached to the shield structure with graphite bolts. In the event of limited aamage, they can be replaced by aeans of an in-vessel manipulator system. Extensive replacement, however, would probably require removal of the sector and replacement of the tiles in the hot cell complex.

The outboard wall, which is less susceptible to impact of disruptions, is protected by means of water cooled, bare stainless steel panels. In order to limit the nunber of coolant connections, these panels are made somewhat larger than can be fitted through available access ports. In addition, the cooling line welds must be made far enough behind the first wall to avoid reweld problems. Accordingly, if a panel must be replaced, the shield sector 


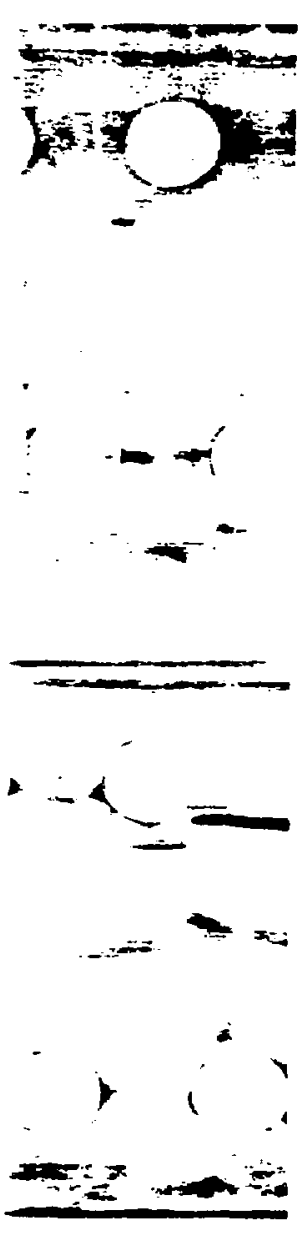

in which it is located must be removed and placed in a hot cell for the replacecent.

7. TEST MODULES

Two of the ten shield sectors are reserved for test modules. Six test modules, each with a frontal area of approximately $1 \mathrm{~m}^{2}$, can be installed in each of the resersed sectors (fig. 8). The test modulus can be used to test first wall concepts, breeding blanket modules, and shield designs (and for limited testing of materials).

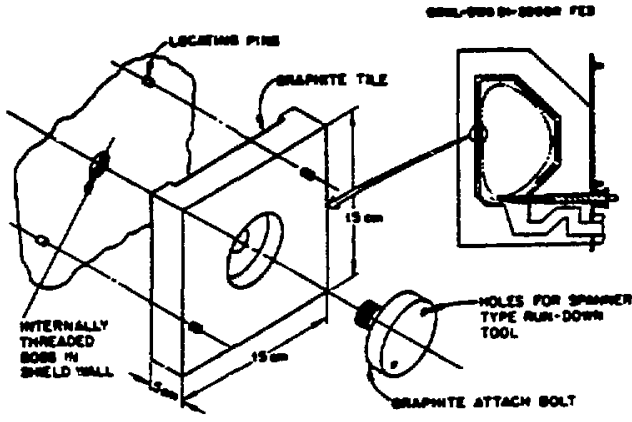

Fig. 7. Passively cooled armor tile.

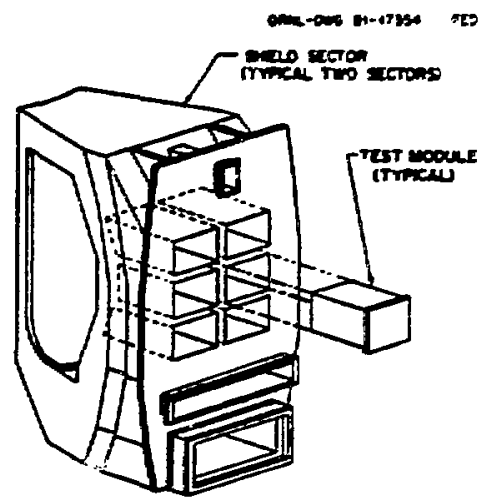

Fig. 8. Test module installation in outboard shield.

The test modules are arranged so that they can be individually installed and removed. Some test stations are equipped with pockets so that the module can be removed without bringing the plasma chamber up to air. Others are left open so that the test modules are exposed to the plasma or to the back side of the filst wall panels.

\section{PLASMA HEATING SYSTEMS}

A combination of poloidal field (PF) induction and rf heating is used for plasma initiation, startup, and bulk heating. One megawatt of electron-cyclotron resonant heating (ECRH) is applied for ionization of the fill gas and heating beyond the point where radiation losses dominate the energy balance. The plasma current is then induced with the PF coil system while the ECRH system remains energized to assist the startup. During the current ramp-up phase, $5 \mathrm{MW}$ of ion-cyclotron resonant heating (ICRH) is applied, and six seconds after the plasma current is initiated, $50 \mathrm{MW}$ of ICRH is applied to raise the temperature of the plasma to burn stage.

The ECRH launchers are located in the top of each of the ten shield sectors. The launcher assemblies are installed at the mid-plane in four adjacent torus sectors such that they can be removed and replaced with procedures similar to those used for the purped limiter ilades.

9. TF COILS

The TF coils are enclosed in a cryostat which envelops the entire assembly of ten coils, except at the outboard legs, which are individually contained. This provides access to the torus through the ten open bays between adjacent pairs of coils.

It: was concluded that the TF coils would have to be designed as highly reliable corponents because of the inherent difficulty in replacing them. Replacement involves removal of at least a part of the torus spool and cryostat as well as at least one torus sector. 

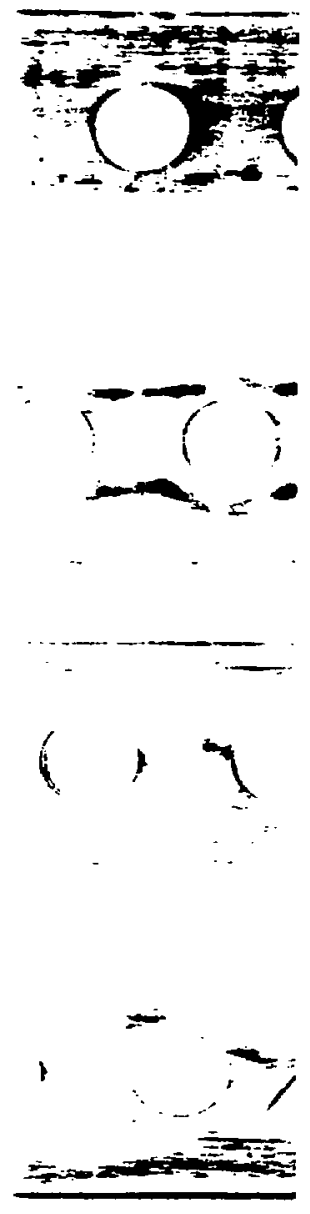

Changes which would enhance the replacement of TF coils, such as the wse of a coeron boundary between the plasma chamber and the TF coil assembly, are being considered.

10. POLOIDAL FIELD COILS

The poloidal field (PF) coil system presents a particularly difficult problew with regard to location and maintenance. In order to minimize the current and power supply requirements, the EF coils should be placed close to the plasea. Locating the EF coils inside the TF coil bore, however, precludes the use of superconducting coils. A compromise solution involving two normal conducting coils in the TF coil bore and two supercondicting coils outside the bore was adopted.

The lower exterior EF coil is effectively trapped in the current design. It nay be possible to wind a new coil in-situ or to design the reactor support system in such a way as to allow lateral movement of the coil by progressively removing individual supports. Alternatively, consideration is being given to making the coil somewhat larger so that it can be vertically removed around the TF coil assembly.

The normal conducting EF coils and control coils located inside the TF coil bore are segmented to permit their removal and replacement without removal of the TF coils. The upper inboard EF coil, for example, has 36 turns and is assembled in two bolted segments per turn.

The central solenoid, which includes both induction $(\mathrm{OH})$ and EF elenents, is designed for removal by removing the cryostat dome and vertically lifting the solenoid.

11. CONCLUSIONS

A design which provides for meeting the mission goals of the FED has been developed. Test modules can be inserted in such a way as to extract thermal power under prototypical conditions and to demonstrate a full fuel cycle operation which can be reflected in fuel self-sufficiency in a fusion demonstration. In addition, the construction, operation, and maintenance of the FED will demonstrate these aspects in a device integrating technologies representative of a fusion demonstration plant.

Special emphasis has been placed on the maintainability of the FED. It is expected that only a limited number of components, such as the limiter blades, will require periodic replacement. The reactor, therefore, is designed for ready access to and replacement of these components.

While the other major components should not require periodic replacement, it is recognized that failures will occur and that ease of replacement is an important consideration. To the extent possible, components are modularized in such a way as to permit convenient replacement.

Two components, the lower outboard EF coil and the TF coils, are recognized as presenting special replacement problems. Studies to ameliorate these concerns are continuing.

REFERENCES

11/ The Fusion Engineering Device - Executive Sumary, DOE/TIC-11600, October 1981.

/2/ Fusion Engineering Device Design Description, ORNL/TM-7C48, December 1981 .

/3/ R. L. Reid, "Oak Ridge TNS Program: Systen Studies of the Toroidal Fieid Coils," ORNL/TM-6723, December 1979. 